\title{
Amelioration of bowel movement by daily ingestion of Kumaizasa (Sasa. senanensis) powder: A placebo-controlled, randomized, double- blind, parallel-group comparison study
}

\begin{abstract}
Jun Nishihira ${ }^{1}$, Hideo Hara ${ }^{2}$, Aiko Tanaka ${ }^{1}$ and Hiroyo Kagami-Katsuyama ${ }^{1}$
${ }^{1}$ Hokkaido Information University, Health Information Science Research Center, Ebetsu, Hokkaido, Japan; ${ }^{2}$ UNIAL Co., Ltd., Hokkaido Bioresources Innovation Center, Itabashi-ku, Tokyo, Japan

Corresponding author: Jun Nishihira, MD, PhD, Health Information Science Research Center, Hokkaido Information University, Nishi Nopporo 59-2, Ebetsu, Hokkaido 069-8585, Japan.

Submission Date: March $12^{\text {th }}, 2019$. Acceptance Date: May $28^{\text {th }}, 2019$. Publication Date: May $30^{\text {st }}$, 2019.

Citation: Nishihira J., Hara H., Tanaka A., Kagami-Katsuyama H. Amelioration of bowel movement by daily ingestion of Kumaizasa (Sasa. senanensis) powder: A placebo-controlled, randomized, doubleblind, parallel-group comparison study. Functional Foods in Health and Disease 2019; 9(5): 341-356. https://doi.org/10.31989/ffhd.v9i5.603
\end{abstract}

\section{ABSTRACT}

Background: Kumaizasa (Sasa. senanensis (Franchet et Savatier) Rehder) is a bush-type bamboo grown in Hokkaido, Japan and has traditionally been used as a material for herbal medicine and health food. The purpose of this study was to investigate the effect of daily ingestion of Kumaizasa powder (4.2g/day) for 2 weeks for improvement of constipation.

Methods: We conducted a placebo-controlled, randomized, double-blind, parallel-group comparison study on 80 healthy Japanese men and women between the ages of 20 and 65 who complained of chronic constipation.

Results: The stool frequency per week as the primary outcome showed a significant increase after 2week ingestion of the active food (Kumaizasa powder) compared with the placebo (starch). The stool odor was also significantly improved after 2-week ingestion of Kumaizasa powder compared with the placebo. Abdominal condition was also significantly improved by visual analogue scale (VAS) evaluation. 
Conclusions: We concluded that daily ingestion of Kumaizasa powder is useful for improvement of constipation.

\section{Clinical trial registration: UMIN000029430}

Keywords: clinical trial, Kumaizasa, constipation

\section{BACKGROUND:}

In recent years in Japan, the prevalence of constipation has increased due to the shift toward high-fat, low-fiber diets, decreasing exercise and of the impacts on the intestinal environment of chronic stress. Constipation is a common symptom in women and the elderly; in this condition, defecation is not performed smoothly and is accompanied by abdominal discomfort including straining, pain, and a sensation of incomplete evacuation. These symptoms not only lower the quality of life (QOL) but also increase the risk of the development of colorectal cancer [1]. In this context, improvement of bowel movement is directly related to the maintenance of good health.

Most cases of constipation are thought to be resolved by improvement of lifestyle and healthy diets, particularly ingestion of dietary fibers [2-4]. For example, ingestion of dietary fiber improved bowel movement, shortening the stool transit time and increasing stool frequency even in young adults [2]. Following that report, a meta-analysis revealed the usefulness of dietary fiber in helping to ameliorate constipation, in particular, stool frequency [5]. Therefore, consumers have expressed a keen interest in health foods that offer easy ingestion of dietary fiber on a daily basis.

Bamboo comprises a group of large woody grasses belonging to the family Poaceae and subfamily Bambusoideae [6]. This subfamily consists of more than 70 genera and about 1,450 species [7]. Among them, Kumaizasa is a bush-type bamboo grown in Hokkaido, Japan and has been used as a material for herbal medicine and as a health food. Kumaizasa is rich in dietary fiber, especially holocellulose. Holocellulose derived from Kumaizasa was confirmed to have an effect of increasing stool weight in preliminary experiments in rats conducted by UNIAL Co., Ltd (Tokyo, Japan, unpublished data) and was suggested to have the potential to improve constipation. In another study, the stool volume and stool frequency significantly improved by continuous ingestion of Kumaizasa powder in female subjects of various ages with chronic constipation [8]. In brief, researchers conducted an open clinical trial of daily ingestion of Kumaizasa powder for 56 subjects aged from 20 to 60 years who complained of persistent constipation. Subjects consumed $4.2 \mathrm{~g}$ /day of Kumaizasa powder at a maximum for 4 weeks. The results showed a significant improvement in stool frequency, shape, color and odor, abdominal condition, and sensation after defecation compared with the placebo. However, no study under placebo-controlled study design has shown that Kumaizasa powder can relieve constipation. Thus, we here conducted a placebo-controlled, randomized, double-blind, parallel-group comparison study to evaluate the effects of Kumaizasa powder in healthy volunteers with a tendency for constipation. 


\section{METHODS}

\section{Study design}

The clinical study was conducted as a placebo-controlled, randomized, double-blind, and parallel-group comparison study. The time schedule for the study is shown in Figure 1. The subjects were recruited by Hokkaido Information University $\left(25^{\text {th }}\right.$ August- $8^{\text {th }}$ September 2017$)$ and were fully informed regarding its content and methods. Written informed consent was obtained from subjects before their enrollment. At visit 1, we performed a medical interview, a check of vital signs, hematological examinations, and body composition measurements for those who met the inclusion criteria and not the exclusion criteria (see 2.2 Subjects) at the time of recruitment. After visit 1, we set a 2-week screening period. During the screening period, subjects were instructed to take approximately $150 \mathrm{ml}$ of water daily after breakfast and asked to record in a diary changes in physical condition, medication and defecation status. Based on the diaries, we selected subjects whose stool frequency was 3 to 5 times per week and allotted them into active and placebo groups. One week before the start of the study food ingestion, we set the preobservation period as the baseline period, during which subjects were instructed to take approximately $150 \mathrm{ml}$ of water daily after breakfast. At, visit 2 (week 0 as the baseline) and visit 3 (week 2), we performed a medical interview, a check of vital signs, hematological examinations, body composition measurements and VAS questionnaires. During the pre-observation period and the study food ingestion period, subjects were asked to record in a diary changes in physical conditions, medication, the study food ingestion (only during the study food ingestion period) and defecation status. Furthermore, the contents of meals for three days before each visit were recorded on questionnaires and submitted at each visit. During the entire course of this study, subjects were asked not to change their daily activities including food consumption and exercise. As for foods to be avoided during the study, ingestion and overdose of the following foods were prohibited during the period from the visit 1 to visit 3: 1) health foods and supplements, including foods for specified health use. 2) foods formulated with oligosaccharides (oligosaccharide powder, oligosaccharide syrup, oligosaccharide-containing beverages). 3) foods enriched with dietary fiber (dietary fiber powder, beverages containing dietary fiber), and 4) yogurt and other beverages containing lactic acid bacteria, 5) natto (traditional Japanese food made from fermented soybeans).

The primary outcome was stool frequency, and the secondary outcomes were stool volume, shape, color, odor, and sensation after defecation and items on a VAS questionnaire including abdominal condition, sensation after defecation, and tension of the lower abdomen. We evaluated the efficacy of the active food at week 2 .

We performed the current clinical trial by the method shown in "Regarding the permission to display foods for specified health use," and "Notes on the application for food for specified health use" [9]. 


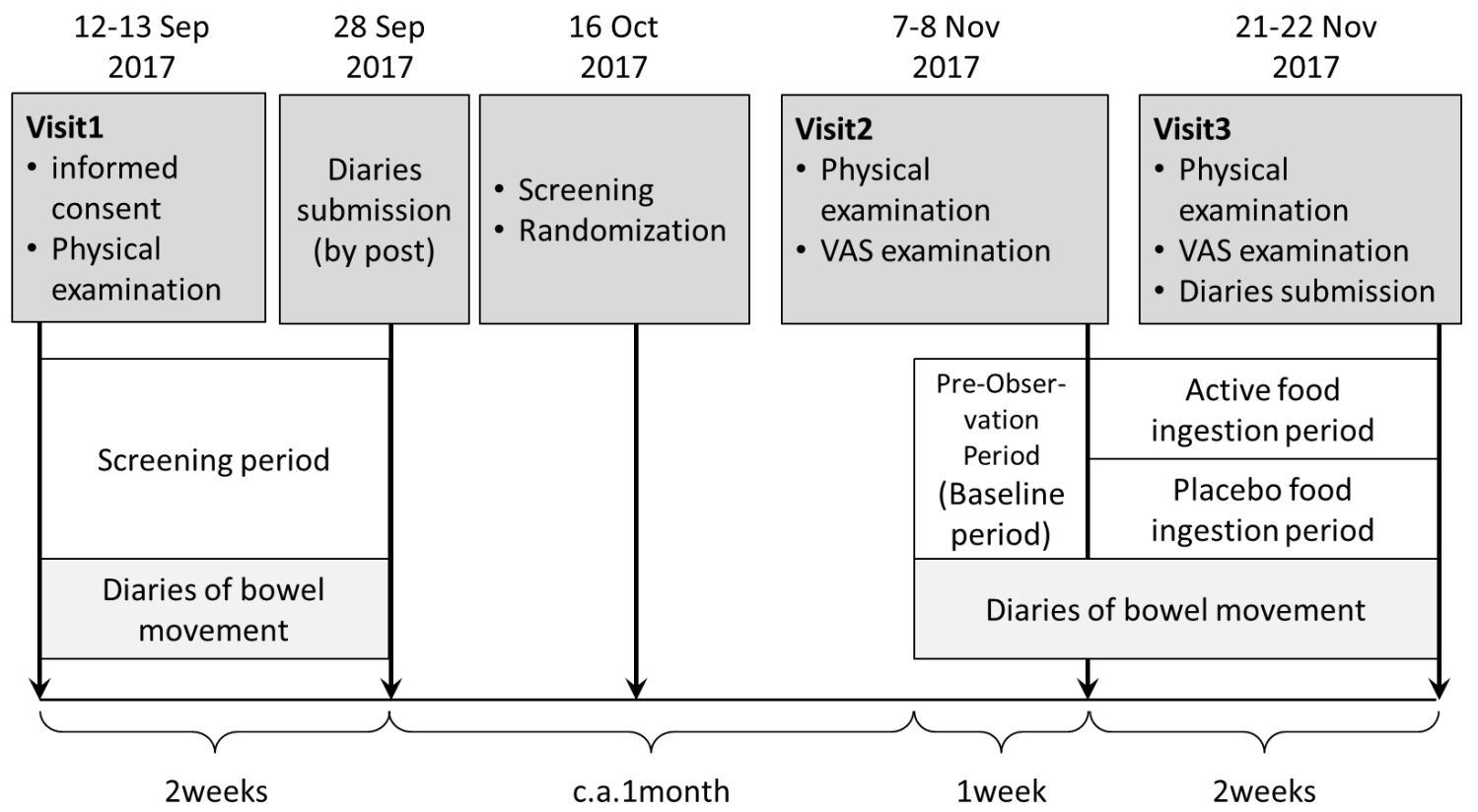

Figure 1. The schedule of the clinical trial.

\section{Subjects}

141 subjects volunteered to participate in the physical examination at visit 1 and recorded their bowel movements in a diary during the screening period. All volunteers provided written informed consent to participate in this clinical study. Through screening tests (physical examination at visit 1 and bowel movement records), we selected 80 healthy Japanese subjects (aged 20-65 years) whose stool frequency was 3-5 times per week during the screening period. The exclusion criteria were 1) subjects having a major surgical history related to the digestive system, 2) subjects with irritable bowel syndrome or inflammatory bowel disease, 3) subjects who regularly take anticoagulants (warfarin), 4) subjects with serious cerebrovascular, cardiac, hepatic, renal, and/or gastrointestinal diseases, or who are affected by an infectious disease that needs to be reported to authorities, 5) subjects with unusually high and/or low BP or abnormal hematological data, 6) subjects with serious anemia, 7) pre- or postmenopausal subjects having complaints of obvious physical changes, 8) subjects who are at risk of having allergic reactions to drugs or foods, especially Poaceae (rice, wheat, corn, etc.), 9) subjects who regularly take medicine, functional foods and/or supplements (antibiotics, digestants, laxatives, antidiarrheals, probiotics, oligosaccharide, dietary fiber, etc.) that would affect defecation, 10) heavy smokers, alcohol addicts or subjects with irregular lifestyles, 11) subjects who donated either $400 \mathrm{ml}$ of whole blood within 12 weeks or $200 \mathrm{ml}$ of whole blood within 4 weeks or blood components within 2 weeks prior to the start of this study, 12) subjects who were pregnant or expected to be pregnant, or lactating during the study, 13) subjects who had participated in other clinical trials within the month prior to the current clinical trial, and 14) any other medical reasons judged by the principal investigator. The 80 eligible subjects were randomly assigned to the active food group (Kumaizasa powder) or the placebo food group stratified by sex, age and stool frequency per week based on per diaries during the screening period. Group assignments were computer-generated using stratified block randomization at 
a third-party data center (Media Educational Center, Hokkaido Institute of Information Technology, Ebetsu city, Hokkaido). Doctors, nurses, clinical research coordinators, and statistical analyzers had no knowledge of the assignment information during this trial period. This information was only disclosed after the laboratory and analytical data were fixed and the method of statistical analysis was finalized.

\section{Study food}

The study foods, i.e., the active food (Kumaizasa powder; SanSTAGE®) and the placebo (starch colored with gardenia), were provided by UNIAL Co., Ltd (Tokyo, Japan). The composition of the study foods used in this study is given in Table 1 . The active food was prepared by powdering and sterilizing Kumaizasa leaves harvested in Hokkaido. The production and packing were carried out in a quality-controlled manufacturing plant in compliance with the Food Sanitation Act (the Ministry of Health, Labor, and Welfare of Japan). Regarding the quality of the active food and placebo foods, both were prepared at a factory where the quality and sanitation system for food processing was strictly controlled for safety before shipment.

The study foods were packed in an aluminum package (4.2 g/package), and there was no difference in appearance between the test foods and the placebo. We instructed subjects to take 1 pack of the study foods each day suspended in $150 \mathrm{ml}$ water at a favorite time (if possible after breakfast) for 2 weeks daily.

Kumaizasa powder has been manufactured and sold by UNIAL Co. Ltd. (Tokyo, Japan) since 1957, and no adverse effects or any other health problems or severe complaints about the food have been claimed. In animal experiments, we confirmed the safety of Kumaizasa powder by a 28-day repeated dose toxicity test (non-toxic dose of less than $2000 \mathrm{mg} / \mathrm{kg}$ of rat males) and micronucleus test (unpublished data). In humans, 56 women between 20 and 60 years old with chronic constipation ingested $4.2 \mathrm{~g}$ /day of Kumaizasa for 4 weeks did not complain of any side effects, such as abdominal pain or diarrhea, and no abnormal laboratory data were found [8].

Table 1. The contents of the study foods

\begin{tabular}{lcc}
\hline & $\begin{array}{c}\text { Placebo } \\
(4.2 \mathrm{~g})\end{array}$ & $\begin{array}{c}\text { Active } \\
(4.2 \mathrm{~g})\end{array}$ \\
\hline Calories (kcal) & 15.0 & 10.8 \\
Water (g) & 0.2 & 0.1 \\
Proteins (g) & 0.0 & 0.6 \\
Lipids (g) & 0.0 & 0.2 \\
Carbohydrates (g) & 3.7 & 3.1 \\
Ash (g) & 0.0 & 0.3 \\
Sodium (mg) & 0.0 & 0.4 \\
Kumaizasa-holocellulose (g) & 0.0 & 2.2 \\
\hline
\end{tabular}

\section{Physical Examination}

Blood samples were taken for testing at week 0 and at weeks 2 . In addition to a medical interview by a 
doctor, each subject's body composition (body weight (BW), body mass index (BMI), body fat ratio (BFR)) and vital signs (blood pressure (BP) and heart rate) at the visit were measured. General blood tests included white blood cell counts (WBC), red blood cell counts (RBC), hemoglobin level (Hb), hematocrit level (Ht), platelet count (Plt), aspartate aminotransferase (AST), alanine aminotransferase (ALT), gamma-glutamyl transpeptidase ( $\gamma$-GTP), alkaline phosphatase (ALP), and lactate dehydrogenase (LDH), blood urea nitrogen (BUN), creatinine (CRE), uric acid (UA), total cholesterol (TC), low-density lipoprotein cholesterol (LDL-C), high-density lipoprotein cholesterol (HLD-C), triglycerides (TG), fasting blood glucose (FBG), and hemoglobin Alc (HbAlc).

\section{Diaries on bowel movement}

During the screening period, pre-observation period and the study food ingestion period, subjects were required to fill out a diary on bowel movement every day regarding six items: stool frequency, volume, shape, color, odor, and sensation after defecation.

Stool frequency was defined as the number of bowel movements per day regardless of the defecation interval or stool volume. Stool volume was determined by naked eyes using a ping-pong ball (diameter $40 \mathrm{~mm}$ ) as a guide, and the corresponding total number was described. Stool shapes were classified into 6 types, including separate nut shape (1 point), hard lump shape (2 points), banana shape ( 3 points), half shape ( 4 points), mud shape ( 5 points), and watery ( 6 points). Stool colors were classified into six: dark brown almost black (1 point), dark brown (2 points), brown (3 points), yellowish brown (4 points), light yellowish brown (5 points), and yellow (6 points). The subjects decided on the type of their stool. The stool odor was selected from 5 types, extreme ( 1 point), strong ( 2 points), average ( 3 points), weak (4 points), and very weak (5 points). The sensation after defecation was selected from four items, very poor (1 point), poor ( 2 points), good ( 3 points), and excellent (4 points).

In cases in which defecation was performed more than once per day, stool shape, stool color, stool odor, and sensation after defecation were recorded only for the first defecation of the day.

We performed 3 evaluations, at baseline (1 week before the study food ingestion), week 1 (first half of the study food ingestion period) and week 2 (last half of the study food ingestion period). As for stool frequency, the total for each period was calculated for each subject. For the total stool volume, shape, color, odor, and sensation after defecation, the average for each period was calculated for each subject.

\section{VAS questionnaire}

Subjects responded to a VAS questionnaire at visit 2 and visit 3, including questions about abdominal condition, sensation after defecation, and tension of the lower abdomen. On a line segment of $100 \mathrm{~mm}$ for each item, subjects marked the specific points (writing an x mark on the line segment) of the worst state at the left end and the state with the best condition at the right end. The questionnaire result was scaled by measuring the lengths from the left end to the two $\mathrm{x}$ marks. 


\section{Food frequency questionnaire}

Based on the 3-day record of the contents of the meal before each visit, a nutritionist calculated the mean values and standard deviation for the intake volume of nutrients (calories, protein, fat, carbohydrates, dietary fiber, and salt) on visit 1 and visit 2 .

\section{Ethics}

We conducted the current clinical trial in compliance with ethical guidelines on medical research on humans (Ministry of Education, Culture, Sports, Science and Technology, and Ministry of Health, Labor and Welfare) and in compliance with the Helsinki Declaration (revised by the Fortaleza General Meeting of the World Medical Association). The study protocol was approved by the Ethics Committee of the Hokkaido Information University (Ebetsu, Hokkaido, Japan, approval date 8 September 2017; approval number: 2017-15). This study was registered at www.umin.ac.jp/ctr/index.htm (registration number: UMIN000029430, date of registration 6 October 2017).

\section{Statistical Analysis}

Means and standard deviations of the subject characteristics were calculated for each group. As for the primary outcome, secondary outcomes, and food frequency questionnaire, changes in subject values were analyzed using Student's t-test by comparing the means between the active food group and the placebo at each evaluation point (period). As for subject characteristics, Fisher's exact probability test was conducted for gender and Mann-Whitney's U test was performed for ingestion rate. Student's ttest was used for the other subject characteristics. The ingestion rate was calculated using the following equation:

(1) Ingestion rate $(\%)=\frac{\text { (Actual number of ingestion study foods) }}{\text { (Scheduled number of ingested study foods })} \times 100 \%$

All statistical analyses were performed using SPSS Statistics 20 (IBM Japan, Ltd), and $\mathrm{p}$ values $<0.05$ were considered to indicate significance.

\section{Sample Size}

Prior to conducting the current study, we performed a placebo-controlled double-blind, parallel group comparison test (registered at www.umin.ac.jp/ctr/index.htm (registration number: UMIN000024504), date of registration 20 October 2016) with the multiple doses of $1.4 \mathrm{~g}, 2.8 \mathrm{~g}$, and $4.2 \mathrm{~g}$. The VAS questionnaire results indicated that bowel movement was improved by continuous 2-week ingestion of $4.2 \mathrm{~g} /$ day of Kumaizasa powder in respect to stool frequency, color and odor, and tension of lower abdomen. Based on the preliminary data, the sample size was calculated to detect an inter-group difference of 1.00 in stool frequency changes from baseline to week 2 (standard deviation $(\mathrm{SD})=0.5$ ), using a two-sided paired t-test with a statistical power of $80 \%$ and an $\alpha$ value of $5 \%$. This determined the total sample size of 72 , plus 8 to allow for attrition. 


\section{RESULTS}

\section{Subject Dropouts and Exclusions, and Characteristics}

The flow of participant involvement through the trial is shown in Figure 2. Subjects who provided consent $(n=141)$ were assessed for eligibility, and a total of 80 subjects were enrolled in the study. All enrolled subjects were randomized into one of the two intervention groups (placebo group, $n=40$; active group, $\mathrm{n}=40$ ). During the trial, 2 subjects dropped out for personal reasons before ingestion of the study foods. As a result, 78 subjects completed this trial, 38 in the active food group and 40 in the placebo; all were included in the safety analysis. One subject was excluded from the efficacy analysis because of protocol violation (too much ingestion of a food rich in dietary fiber).

Gender ratio, mean age, height, BW, BFR, BMI, baseline stool frequency per week and ingestion rate for each group are presented in Table 2. There was no significant difference between the active food group and the placebo for any baseline variable. Also, no statistically significant differences were observed on the food frequency questionnaire between the active food group and the placebo.

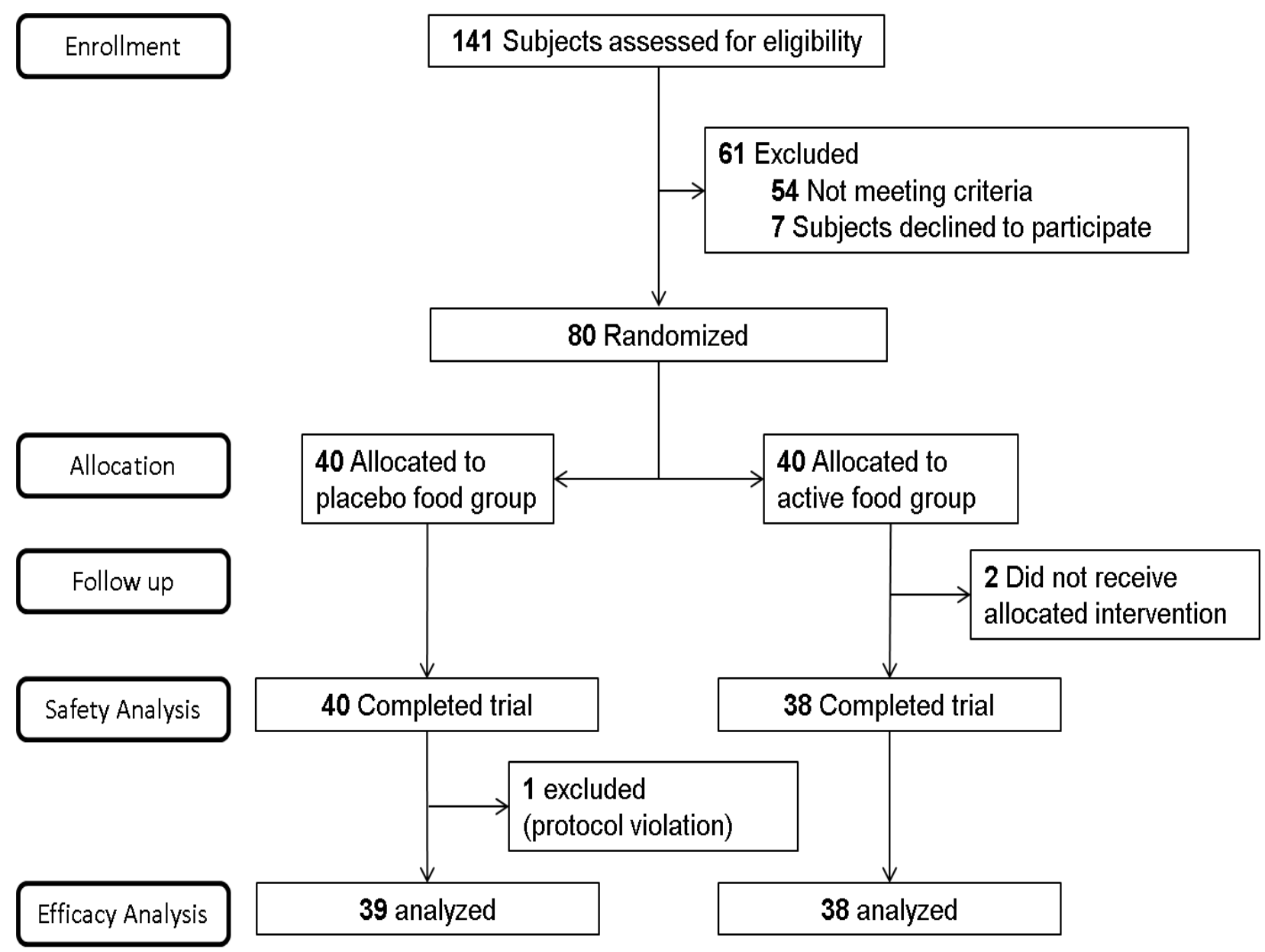


Figure 2. Flowchart of selection for subjects. Values are expressed as the number of subjects.

Table 2. Demographic data

\begin{tabular}{lccc}
\hline Characteristic & Placebo & Active & $p$-value \\
\hline Subjects (n) & 39 & 38 & - \\
Gender (male/female) (n) & $1 / 38$ & $2 / 36$ & 0.615 \\
Age (years) & $49.95 \pm 8.56$ & $50.34 \pm 7.85$ & 0.834 \\
Height (cm) & $159.49 \pm 4.88$ & $157.14 \pm 6.04$ & 0.064 \\
BW (kg) & $53.49 \pm 8.57$ & $52.16 \pm 7.40$ & 0.468 \\
BFR (\%) & $28.36 \pm 6.54$ & $28.37 \pm 6.23$ & 0.993 \\
BMI (kg/cm $\left.{ }^{2}\right)$ & $21.02 \pm 3.22$ & $21.13 \pm 2.82$ & 0.876 \\
Stool frequency per week (times) & $3.64 \pm 1.16$ & $3.66 \pm 1.24$ & 0.951 \\
Intake rate (\%) & $100.00 \pm 0.00$ & $99.81 \pm 0.01$ & 0.311 \\
\hline
\end{tabular}

Values are shown as the mean \pm standard deviation.

\section{Efficacy of Active Food (Kumaizasa powder) on Stool Frequency}

After 2 weeks' ingestion of the study foods, the active food group showed a significantly higher value for stool frequency compared with the placebo group. The defecation frequencies of the placebo at baseline, week 1 and week 2 were $4.08 \pm 1.53$ times, $4.59 \pm 1.62$ times, and $4.46 \pm 1.45$ times, respectively. On the other hand, stool frequency of the active at baseline, week 1, and week 2 were 3.74 \pm 1.31 times, $4.76 \pm 1.67$ times, $5.50 \pm 2.35$ times, respectively (Fig. 3(a), Table 3).

The change from baseline to week 1 and the change from baseline to week 2 were $0.51 \pm 1.73$ times and $0.38 \pm 2.02$ times in the placebo group, respectively. This was compared to $1.03 \pm 1.50$ times and $1.76 \pm 2.16$ times in the active food group, respectively (Fig. 3(b), Table 3). At week 1, there was no significant difference between the active and placebo groups $(p=0.168)$, but at week 2 , there was a significant difference $(p=0.005)$ (Fig. 3(b), Table 3).

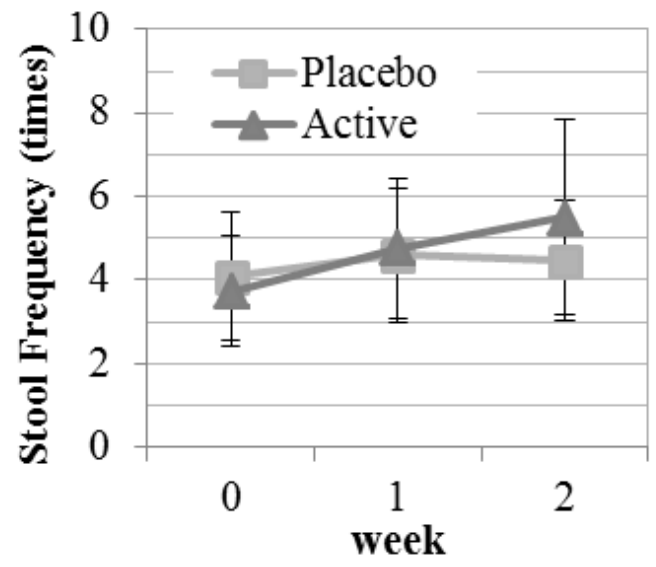

(a)

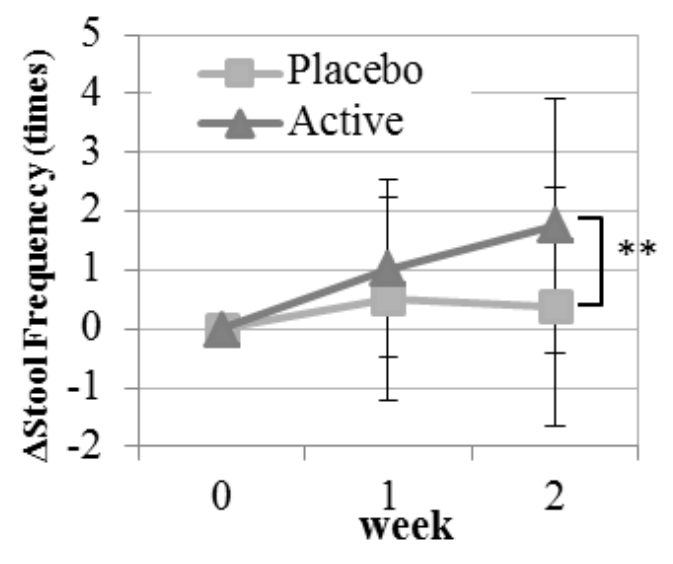

(b)

Figure 3. Stool frequencyValues are means \pm standard deviation. (a) Stool frequency; (b) Changes in stool frequency. Black bar, active food group; Gray bar, placebo food group. Student's t-test was performed to analyze the values. Statistical significance: ** $p<0.01$ vs. placebo group. 
Table 3. The results of the Physical Examination

\begin{tabular}{|c|c|c|c|c|c|c|c|c|c|c|c|c|c|c|c|c|}
\hline & & Week & & & Weel & & & Week & & & $\Delta \mathbf{1 w}$ & & & $\Delta 2$ wee & & \\
\hline \multirow{3}{*}{$\begin{array}{l}\text { Stool Frequency } \\
\text { (times) }\end{array}$} & Placebo & 4.08 & \pm & 1.53 & 4.59 & \pm & 1.62 & 4.46 & \pm & 1.45 & 0.51 & \pm & 1.73 & 0.38 & \pm & 2.02 \\
\hline & Active & 3.74 & \pm & 1.31 & 4.76 & \pm & 1.67 & 5.50 & \pm & 2.35 & 1.03 & \pm & 1.50 & 1.76 & \pm & 2.16 \\
\hline & $p$-value & - & & & - & & & - & & & 0.168 & & & $0.005^{* * *}$ & & \\
\hline \multirow{3}{*}{ Stool volume } & Placebo & 3.10 & \pm & 1.77 & 3.13 & \pm & 1.80 & 3.26 & \pm & 1.86 & 0.03 & \pm & 1.74 & 0.16 & \pm & 2.16 \\
\hline & Active & 3.53 & \pm & 2.05 & 3.48 & \pm & 1.77 & 3.71 & \pm & 1.67 & -0.05 & \pm & 1.95 & 0.18 & \pm & 1.88 \\
\hline & $p$-value & - & & & - & & & - & & & 0.854 & & & 0.961 & & \\
\hline \multirow{3}{*}{ Stool shape } & Placebo & 2.41 & \pm & 0.84 & 2.53 & \pm & 0.86 & 2.53 & \pm & 0.71 & 0.12 & \pm & 0.79 & 0.12 & \pm & 0.83 \\
\hline & Active & 2.57 & \pm & 0.91 & 2.67 & \pm & 0.82 & 2.61 & \pm & 0.75 & 0.10 & \pm & 0.72 & 0.04 & \pm & 0.70 \\
\hline & $p$-value & - & & & - & & & - & & & 0.921 & & & 0.672 & & \\
\hline \multirow{3}{*}{ Stool color } & Placebo & 2.55 & \pm & 0.81 & 2.59 & \pm & 0.64 & 2.76 & \pm & 0.72 & 0.04 & \pm & 0.59 & 0.21 & \pm & 0.60 \\
\hline & Active & 2.47 & \pm & 0.75 & 2.64 & \pm & 0.56 & 2.81 & \pm & 0.62 & 0.17 & \pm & 0.65 & 0.34 & \pm & 0.77 \\
\hline & $p$-value & - & & & - & & & - & & & 0.356 & & & 0.411 & & \\
\hline \multirow{3}{*}{ Stool } & Placebo & 2.70 & \pm & 0.52 & 2.80 & \pm & 0.48 & 2.77 & \pm & 0.56 & 0.10 & \pm & 0.51 & 0.07 & \pm & 0.56 \\
\hline & Active & 2.60 & \pm & 0.61 & 2.87 & \pm & 0.61 & 2.93 & \pm & 0.48 & 0.28 & \pm & 0.42 & 0.33 & \pm & 0.49 \\
\hline & $p$-value & - & & & - & & & - & & & 0.100 & & & $0.036^{*}$ & & \\
\hline Sensation after & Placebo & 2.39 & \pm & 0.60 & 2.56 & \pm & 0.80 & 2.78 & \pm & 0.75 & 0.16 & \pm & 0.56 & 0.39 & \pm & 0.60 \\
\hline defecation & Active & 2.33 & \pm & 0.73 & 2.53 & \pm & 0.69 & 2.72 & \pm & 0.68 & 0.20 & \pm & 0.59 & 0.40 & \pm & 0.62 \\
\hline (points) & $p$-value & - & & & - & & & - & & & 0.753 & & & 0.966 & & \\
\hline \multirow{3}{*}{$\begin{array}{l}\text { VAS-abdominal } \\
\text { condition }(\mathbf{m m})\end{array}$} & Placebo & 53.46 & \pm & 10.38 & - & & & 57.49 & \pm & 14.88 & - & & & 6.87 & \pm & 12.26 \\
\hline & Active & 51.45 & \pm & 13.38 & - & & & 62.26 & \pm & 14.02 & - & & & 14.39 & \pm & 17.68 \\
\hline & $p$-value & - & & & - & & & - & & & - & & & $0.042 *$ & & \\
\hline VAS-sensation & Placebo & 50.62 & \pm & 12.19 & - & & & 60.59 & \pm & 19.97 & - & & & 9.03 & \pm & 22.56 \\
\hline after defecation & Active & $\mathbf{5 0 . 0 0}$ & \pm & 10.95 & - & & & 68.82 & \pm & 18.42 & - & & & 16.16 & \pm & 22.21 \\
\hline (mm) & $p$-value & - & & & - & & & - & & & - & & & 0.146 & & \\
\hline VAS-lower & Placebo & 51.56 & \pm & 18.50 & - & & & 56.36 & \pm & 14.71 & - & & & 9.03 & \pm & 22.56 \\
\hline abdominal & Active & 52.66 & \pm & 19.05 & - & & & 61.87 & \pm & 14.90 & - & & & 16.16 & \pm & 22.21 \\
\hline tension $(\mathrm{mm})$ & $p$-value & - & & & - & & & - & & & - & & & 0.166 & & \\
\hline
\end{tabular}

Values are shown as means \pm standard deviations. Student's t-test was performed to analyze the values. Statistical significance: $* p<0.05, * * p<0.01$ vs. placebo group.

\section{Efficacy of Active Food (Kumaizasa powder) on Stool Odor}

After 2-weeks ingestion of the study foods, the active food group showed a significantly higher value for stool odor compared with the placebo. The points of stool odor as for the placebo, baseline, week 1 and week 2 were $2.70 \pm 0.52$ points, $2.80 \pm 0.48$ points, and $2.77 \pm 0.56$ points, respectively, compared to $2.60 \pm 0.61$ points, $2.87 \pm 0.61$ points, and $2.93 \pm 0.48$ points for the active food, respectively (Fig. 4(a), Table 3). 
The change from baseline to week 1 and the change from the baseline to week 2 were $0.10 \pm 0.51$ points and $0.07 \pm 0.56$ points in the placebo food group, respectively, compared to $0.28 \pm 0.42$ points and $0.33 \pm 0.49$ points for the active food group, respectively (Fig. 4(b)). At week 1, there was no significant difference between the active food group and the placebo $(p=0.100)$, but at week 2 , there was a significant difference ( $p=0.036)$ (Fig. 4(b), Table 3).

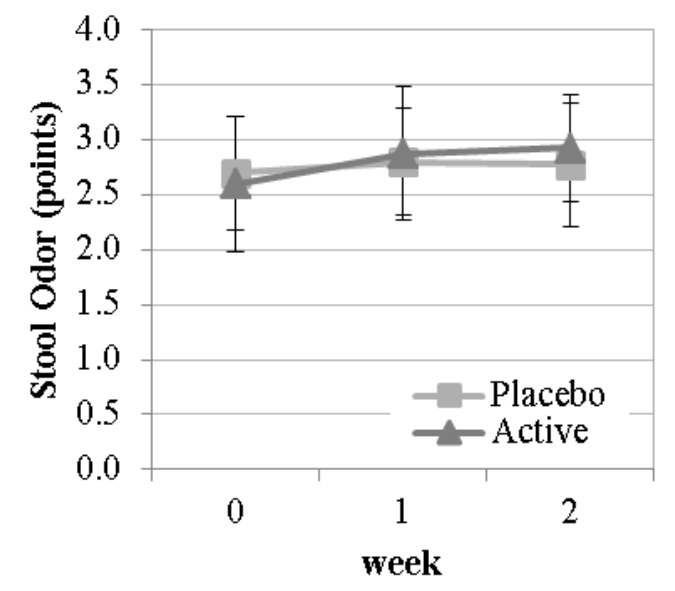

(a)

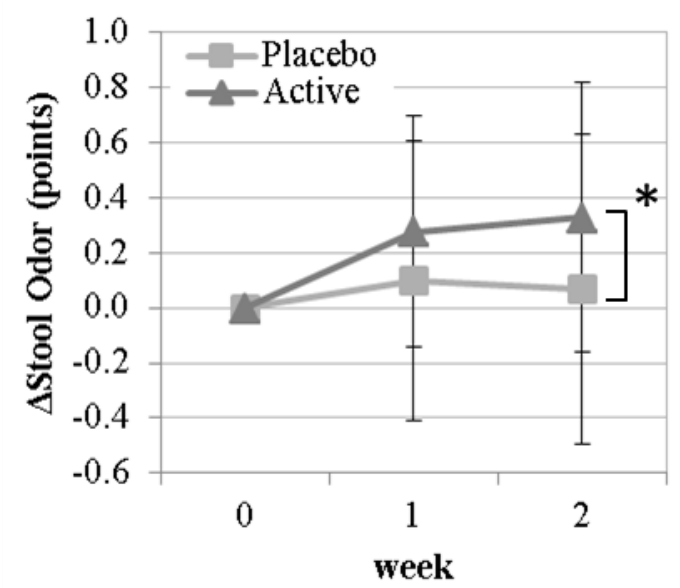

(b)

Figure 4. Stool odor

Values are means \pm standard deviations. (a) Stool odor; (b) Changes in stool odor. Black bar, active food group; Gray bar, placebo food group. Student's t-test was performed to analyze the values. Statistical significance: $* p<0.05$ vs. placebo group.

\section{Efficacy of Active Food (Kumaizasa powder) on Other Parameters Based on Diaries on Bowel Movement}

We also examined other defecation-related items based on diaries on stool volume, shape, andcolor, bowel movement, and sensation after defecation. There were no statistically significant differences between the placebo and the active food (Table 3).

\section{VAS Questionnaire}

We administered a VAS questionnaire on three items: abdominal condition, sensation after defecation and lower abdominal tension.

On the item of abdominal condition, the values were $53.46 \pm 10.38 \mathrm{~mm}$ before the ingestion and $57.49 \pm 14.88 \mathrm{~mm}$ after the ingestion for the placebo, but $51.45 \pm 13.38 \mathrm{~mm}$ before ingestion and 62.26 $\pm 14.02 \mathrm{~mm}$ after ingestion for the active food (Fig. 5(a), Table 3). The change from baseline to 2 weeks was $6.87 \pm 14.39 \mathrm{~mm}$ for the placebo, compared to $12.26 \pm 17.68 \mathrm{~mm}$ for the active food (Fig. $5(\mathrm{~b})$ ). There was a significant difference $(p=0.036)$ between groups. 
On the items on sensation after defecation and lower abdominal tension, 2 weeks ingestion showed apparent improvement compared to baseline values, but the results were not significantly different between the placebo and the active groups.

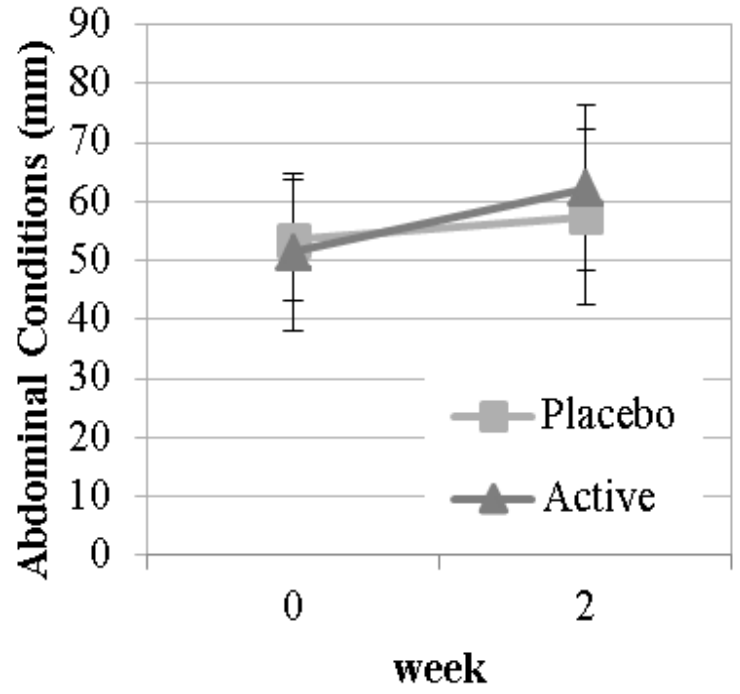

(a)

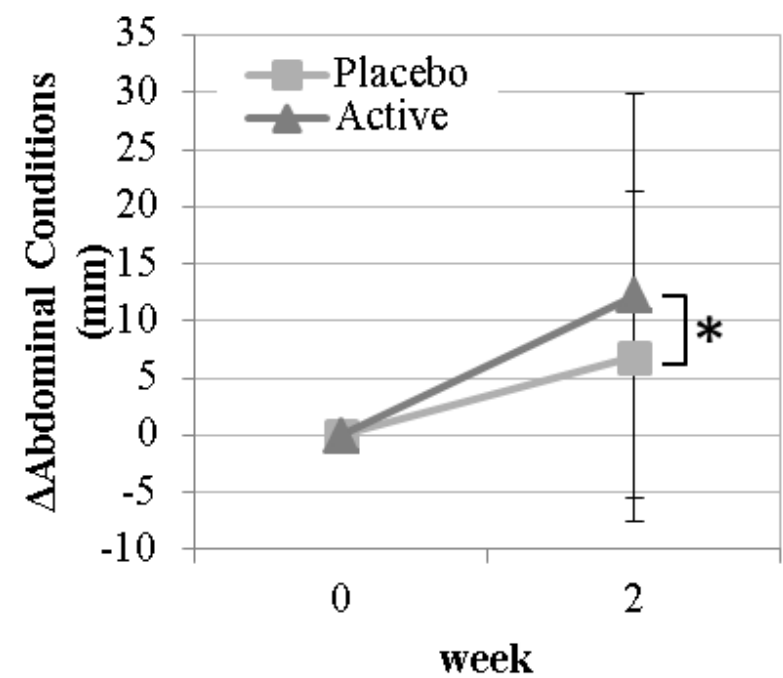

(b)

Figure 5. Abdominal condition (VAS questionnaire)

Values are means \pm standard deviations. (a) Abdominal Conditions; (b) Changes in abdominal Conditions. Black bar, active food group; Gray bar, placebo food group. Student's t-test was performed to analyze the values. Statistical significance: ${ }^{*} p<0.05$ vs. placebo group.

\section{Food Safety}

As for food safety analysis of the active food (Kumaizasa powder), we examined blood test items (WBC, RBC, Hb, Ht, Plt), liver function (AST, ALT, $\gamma$-GTP, ALP, LDH), blood glucose levels (FBG, HbA1c), blood lipids (TC, LDL-C, HDL-C, TG), renal function (BUN, CRE, UA), body composition (BW, BMI, BFR) and vital signs (BP, heart rate) (Table 4). We identified no significant abnormal physical or biological data or clinical signs during the clinical trial. There were also no severe adverse events observed in the medical interview during this study. A few subjects exhibited adverse effects such as headaches or common cold symptoms; moreover, these subjects presented only mild symptoms and recovered within a few days. Therefore, the physician in charge judged there were no adverse events related to the ingestion of $4.2 \mathrm{~g}$ of Kumaizasa powder for 2 weeks. 
Table 4. Results of the Physical Examination

\begin{tabular}{|c|c|c|c|}
\hline & & Week 0 & Week 2 \\
\hline \multirow[t]{2}{*}{$\mathrm{WBC}\left(\times 10^{3} / \mu \mathrm{l}\right)$} & Placebo & $5.35 \pm 1.17$ & $5.06 \pm 1.14$ \\
\hline & Active & $5.14 \pm 1.41$ & $5.37 \pm 1.88$ \\
\hline \multirow[t]{2}{*}{$\mathrm{RBC}\left(\times 10^{4} / \mu \mathrm{l}\right)$} & Placebo & $441.38 \pm 32.99$ & $439.55 \pm 33.00$ \\
\hline & Active & $451.95 \pm 33.05$ & $452.55 \pm 34.15$ \\
\hline \multirow[t]{2}{*}{$\mathrm{Hb}(\mathrm{g} / \mathrm{dl})$} & Placebo & $12.94 \pm 1.09$ & $12.93 \pm 1.17$ \\
\hline & Active & $13.13 \pm 1.44$ & $13.17 \pm 1.63$ \\
\hline \multirow[t]{2}{*}{ Ht (\%) } & Placebo & $39.62 \pm 2.84$ & $39.56 \pm 2.94$ \\
\hline & Active & $39.83 \pm 3.36$ & $40.09 \pm 3.94$ \\
\hline \multirow[t]{2}{*}{ PIt $\left(\times 10^{4} / \mu \mathrm{l}\right)$} & Placebo & $26.58 \pm 5.87$ & $26.27 \pm 5.70$ \\
\hline & Active & $26.83 \pm 6.88$ & $27.31 \pm 6.33$ \\
\hline \multirow[t]{2}{*}{ AST (U/l) } & Placebo & $20.93 \pm 5.03$ & $20.68 \pm 4.71$ \\
\hline & Active & $21.68 \pm 4.36$ & $20.89 \pm 4.92$ \\
\hline \multirow[t]{2}{*}{ ALT (U/l) } & Placebo & $17.00 \pm 9.68$ & $16.40 \pm 7.63$ \\
\hline & Active & $18.34 \pm 8.49$ & $17.76 \pm 8.63$ \\
\hline \multirow[t]{2}{*}{$\gamma-\mathbf{G T P}(\mathrm{U} / \mathrm{l})$} & Placebo & $23.58 \pm 22.24$ & $23.25 \pm 21.02$ \\
\hline & Active & $23.50 \pm 17.74$ & $24.11 \pm 21.90$ \\
\hline \multirow[t]{2}{*}{$\operatorname{ALP}(\mathbf{U} / \mathbf{l})$} & Placebo & $183.28 \pm 51.23$ & $178.75 \pm 49.13$ \\
\hline & Active & $190.45 \pm 76.38$ & $192.95 \pm 90.73$ \\
\hline \multirow[t]{2}{*}{ LDH (U/l) } & Placebo & $174.53 \pm 25.32$ & $176.60 \pm 22.03$ \\
\hline & Active & $189.66 \pm 32.98$ & $185.95 \pm 33.49$ \\
\hline \multirow[t]{2}{*}{ BUN (mg/dl) } & Placebo & $13.63 \pm 3.46$ & $12.86 \pm 3.43$ \\
\hline & Active & $12.25 \pm 2.40$ & $12.17 \pm 2.58$ \\
\hline \multirow[t]{2}{*}{ CRE (mg/dl) } & Placebo & $0.71 \pm 0.07$ & $0.69 \pm 0.08$ \\
\hline & Active & $0.66 \pm 0.08$ & $0.66 \pm 0.09$ \\
\hline \multirow[t]{2}{*}{ UA (mg/dl) } & Placebo & $4.46 \pm 0.92$ & $4.37 \pm 0.98$ \\
\hline & Active & $4.40 \pm 0.99$ & $4.34 \pm 1.03$ \\
\hline \multirow[t]{2}{*}{ TC (mg/dl) } & Placebo & $220.43 \pm 37.58$ & $216.25 \pm 31.47$ \\
\hline & Active & $227.79 \pm 37.17$ & $227.82 \pm 43.34$ \\
\hline \multirow[t]{2}{*}{ LDL-C (mg/dl) } & Placebo & $128.20 \pm 31.02$ & $124.78 \pm 26.31$ \\
\hline & Active & $136.16 \pm 30.44$ & $136.92 \pm 35.48$ \\
\hline \multirow[t]{2}{*}{ HDL-C (mg/dl) } & Placebo & $77.65 \pm 16.96$ & $79.75 \pm 16.50$ \\
\hline & Active & $75.00 \pm 16.24$ & $77.16 \pm 18.17$ \\
\hline \multirow[t]{2}{*}{ TG (mg/dl) } & Placebo & $74.80 \pm 36.17$ & $72.03 \pm 29.05$ \\
\hline & Active & $85.32 \pm 50.31$ & $80.18 \pm 42.27$ \\
\hline \multirow[t]{2}{*}{ FBG (mg/dl) } & Placebo & $85.58 \pm 6.03$ & $88.10 \pm 5.64$ \\
\hline & Active & $86.53 \pm 5.36$ & $88.24 \pm 5.68$ \\
\hline \multirow[t]{2}{*}{ HbA1c (\%) } & Placebo & $5.37 \pm 0.23$ & $5.29 \pm 0.25$ \\
\hline & Active & $5.37 \pm 0.16$ & $5.26 \pm 0.18$ \\
\hline
\end{tabular}

Values are shown as means \pm standard deviations. 


\section{DISCUSSION}

Kumaizasa exerts various health benefits, such ameliration of constipation, potentiation of natural killer cell activity, and improvement of the condition of intestinal environment [8]. In this study, we focused on improvement of consitation by Kumaizasa. Constipation is a state resulting from a disruption of the regular rhythm of defecation, whereby the stool remains in the colon for a long time. Constipation brings about many physical troubles such as abdominal discomfort, bad breath, strong body odor, headache, shoulder discomfort, pimples, swelling and/or fatigue, all of which seriously affect QOL [10]. Constipation is a widespread health problem, and a wide range of treatment methods are used to address it. Lifestyle modification is necessary as a first-line treatment, but data on the effectiveness of these measures are limited. Laxatives are the next choice for the treatment of constipation, but frequent use of these drugs may lead to adverse effects, and alternative treatment measures are therefore needed [5]. In this study, we examined the usefulness of Kumaizasa powder as a fiber supplement to ameliorate constipation by a placebo-controlled, randomized, double-blind, parallel-group comparison study. As a result, stool frequency significantly increased as the primary outcome; also, stool odor and abdominal condition were improved after 2-week ingestion of Kumaizasa powder. These results suggest that Kumaizasa powder can relieve constipation. Kumaizasa has been widely ingested with an expectation of ameliorating constipation in Japan. A previous open clinical trial showed that stool volume and frequency significantly improved by continuous ingestion of Kumaizasa powder in female subjects of various ages with chronic constipation [8]. However, our study is the first study to confirm the efficacy of Kumaizasa for defecation under a placebo-controlled, randomized, double-blind, parallel-group comparison trial. It should be noted that as for stool volume there were no differences between the active food group and the placebo in this study, but that is likely because data about total daily stool volume was not available, only the amount of the first defecation of the day.

For centuries, bamboo shoots and leaves, including Kumaizasa have been traditionally consumed as a functional food, complementary medicine and food additives [6]. Kumaizasa is rich in dietary fiber, especially holocellulose. Ingestion of dietary fiber improves bowel movement, including shortening of stool transit time and stool frequency even in young adults [2]. Following that report, a meta-analysis revealed that dietary fiber ingestion is a potential therapeutic method for addressing constipation [5]. As for the mechanism of dietary fiber on defecation, it is considered that dietary fiber has the ability to increase stool weight. The increased weight is due to the physical presence of the fiber, water held by the fiber, and increased bacterial mass from fermentation. Larger and softer stools increase the ease of defecation and reduce transit time through the intestinal tract, which may help to prevent or relieve constipation [12].

As for the food safety of Kumaizasa powder, we found no adverse events related to the ingestion of the test food. It is notable that no one claimed diarrhea or stomach ache from daily ingestion of Kumaizasa powder. Therefore, Kumaizasa powder can be considered beneficial for amelioration of constipation without having any adverse effects.

In conclusion, our study showed amelioration of constipation by daily ingestion of Kumaizasa 
powder in healthy Japanese subjects aged 20-65 years (active food group, $49.94 \pm 8.56$; placebo food group, $50.34 \pm 7.85)$. However, it is well known that the prevalence of constipation increases with age. Laxatives remain a major treatment to solve the problem, but safety concerns in the frail elderly should be addressed [13]. Kumaizasa may have the potential to ameliorate constipation in the elderly without safety concerns. Moreover, Kumaizasa possesses advantage over other laxative products with respect to taste which encourages long-term use for consumers. Further study investigating the effect and safety of its ingestion among the elderly is expected. However, as a limitation of our study, we examined the effects of Kumaizasa powder only on healthy constipated subjects. Thus, it remains unknown whether Kumaizasa powder could improve constipation for diseased subjects. This issue also should be examined.

\section{CONCLUSION}

In this study, we revealed that Kumaizasa powder could ameliorate constipation without any adverse effects.

Competing Interests: Under the "Hokkaido Information University Bioethics Committee Regulations," the research director and the investigator of this study declared necessary matters concerning conflicts of interest to the ethical review committee and obtained the appropriate review and approval. H.H. is an employee of the UNIAL Co. LTD, which provided financial support for this study, but did not contribute in any other way to the conduct of the study.

Authors' Contributions: Conceptualization, J.N. and H.H.; Methodology, J.N., H.H. and A.T.; Software, H.K.K.; Validation, J.N., H.H. and A.T.; Formal Analysis, H.K.K.; Investigation, J.N., H.H. and A.T.; Resources, H.H.; Data Curation, J.N. and H.K.K.; Writing-Original Draft Preparation, J.N., H.H. and H.K.K.; Writing-Review \& Editing, J.N., H.H. and H.K.K.; Visualization, A.T. and H.K.K.; Supervision, J.N. and H.H.; Project Administration, J.N. and H.H.; Funding Acquisition, J.N. and H.H.

Acknowledgments and Funcding: We are grateful to the members of Hokkaido Information University, Center of Health Information Science (Y. Fukuda, T. Saito, Y. Anzai, N. Shima, and N. Ito) for their technical assistance during the clinical trial.

This study was conducted with research funds under contract with UNIAL Co., LTD. and supported in part by Grants-in-Aid for Regional R\&D Proposal-Based Program from Northern Advancement Center for Science \& Technology of Hokkaido Japan.

\section{REFERENCES}

1. Tashiro N, Budhathoki S, Ohnaka K, Toyomura K, Kono S, Ueki T, Tanaka M, Kakeji Y, Maehara Y, Okamura T, Ikejiri K, Futami K, Maekawa T, Yasunami Y, Takenaka K, Ichimiya H, Terasaka R. Constipation and colorectal cancer risk: the Fukuoka Colorectal Cancer Study. 
Asian Pac J Cancer Prev 2011, 12(8): 2025-30.

2. Saito T, Hayakawa T, Nakamura K, Takita T, Suzuki K, Innami S. Fecal output, gastrointestinal transit time, frequency of evacuation and apparent excretion rate of dietary fiber in young men given diets containing different levels of dietary fiber. J Nutr Sci Vitaminol (Tokyo) 1991, 37(5): 493-508.

3. Eastwood MA, Kirkpatrick JR, Mitchell WD, Bone A, Hamilton T. Effects of dietary supplements of wheat bran and cellulose on faeces and bowel function. Br Med J 1973, 4(5889): 392-4.

4. Spiller GA, Chernoff MC, Hill RA, Gates JE, Nassar JJ, Shipley EA. Effect of purified cellulose, pectin, and a low-residue diet on fecal volatile fatty acids, transit time, and fecal weight in humans. Am J Clin Nutr 1980, 33(4): 754-9.

5. Yang J, Wang HP, Zhou L, Xu CF. Effect of dietary fiber on constipation: a meta analysis. World J Gastroenterol 2012, 18(48): 7378-83.

6. Singhal P, Bal LM, Satya S, Sudhakar P, Naik SN. Bamboo shoots: a novel source of nutrition and medicine. Crit Rev Food Sci Nutr 2013, 53(5): 517-34.

7. Gratani L, Crescente MF, Varone L, Fabrini G, Digiulio E. Growth pattern and photosynthetic activity of different bamboo species growing in the Botanical Garden of Rome. Flora - Morphology, Distribution, Functional Ecology of Plants 2008, 203(1): 77-84.

8. Hara T, Ebihara M, Suzuki M, Numata H, Yagi Y. Effects of "Kumaizasa Powder Tablets" on Natural Killer Cell Activity and Intestinal Environment: Open Clinical Trial. Food Function 2010, 6 (1): 2-7.

9. Consumer Affairs Agency: Attachment 2 of "Consignment Permission on Specified Health Use Foods etc." (October 30, 2014, table 259) "on the application for preparing an application for food for specified health use Points to keep in mind." Available online: http://www.caa.go.jp/foods/pdf/syokuhin1510.pdf (Accessed on 27th Jul 2018).

10. Hiratsuka H. Quality of Life in Gastroenterological Disorders. Quality of Life in People with Constipation. Clinical Gastroenterology 2000, 15: 47-54.

11. Zhang JJ, Liu M, Li Y, Zhou T, Xu DP, Li HB. Nutrition Values and Biological Activities of Bamboo Shoots and Leaves. International Journal of Food Nutrition and Safety 2016, 7(2): 98-108. 